REVISTA X, Curitiba, volume 13, n.2,p.47-66, 2018.

\title{
QUE LÍNGUA FALAMOS? QUE LÍNGUA ENSINAMOS?
}

What Language Do We Speak? What Language Do We Teach?

\section{Rafaela KESSLER KIST (UFPR) ${ }^{1}$}

RESUMO: Este artigo é resultado de um trabalho elaborado na disciplina "Agência, Identidade e Discurso", da Pós-Graduação em Letras na área de Estudos Linguísticos pela Universidade Federal do Paraná. Tem como objetivo observar e analisar trechos do documento oficial de ensino de Língua Portuguesa do Estado do Paraná - DCE, com o intento de refletir acerca de como a língua e o ensino de Língua Portuguesa foram construídos/discursivizados nesse documento, além de verificar a concepção de língua abordada nessa diretriz. Como aporte teórico para realização deste trabalho recorremos a autores como Makoni e Pennycook (2006 e 2010), que discutem a questão da língua como invenção política, alguns pontos a respeito do translingualismo defendidas por Canagarajah (2013). Além de questões acerca da ideia de rizoma levantadas por Deleuze e Guatarri (2006) e Jordão e Fogaça (2012). Como ideia final, apresentamos uma alternativa de desengessamento do caminho apresentado pelo ensino de língua portuguesa do documento oficial de ensino do Estado do Paraná.

PALAVRAS-CHAVE: Ensino de Língua Portuguesa; Documento Oficial de Ensino; Rizoma.

ABSTRACT: This article is the result of a paper elaborated in the discipline "Agency, Identity and Discourse", of the Post-Graduation in Letters in the area of Linguistic Studies by the Federal University of Paraná. The purpose of this study was to observe and analyze excerpts of the official document of the Portuguese language teaching document of the State of Paraná- DCE, with the aim of reflecting on how language and Portuguese Language teaching were constructed/discursed in this document, as well as verifying the conception of language addressed in this guideline. As a theoretical contribution to this work we have recourse to authors such as Makoni and Pennycook (2006 and 2010), who discuss the question of language as a political invention, some points about the translingualism defended by Canagarajah (2013). In addition to issues about the idea of rhizome addressed by Deleuze and Guatarri (2006) and Jordão and Fogaça (2012). As a final idea, we present an alternative of disengaging the path presented by the Portuguese Language teaching of the teaching official document of the State of Paraná.

KEYWORDS: Teaching Portuguese Language; Official Teaching Document; Rhizome.

\footnotetext{
${ }^{1}$ Mestranda e bolsista (Capes) do Programa de Pós-Graduação em Letras - Área de Estudos Linguísticos pela Universidade Federal do Paraná - UFPR. E-mail: rafaela.kessler@gmail.com.
} 
REVISTA X, Curitiba, volume 13, n.2,p.47-66, 2018.

\section{PALAVRAS DE INTRODUÇÃO}

Com as transformações sociais e os frutos resultantes da globalização, vivemos em um meio no qual a língua(gem) ocupa um papel central no modo de organização social e que, consequentemente, recai sob a forma de como os sujeitos se identificam e produzem sentido na/pela sua língua. Assim, faz-se necessário considerar os efeitos desse processo sobre a língua(gem), pois a globalização é um dos fatores que provoca o fluxo e a movimentação de pessoas, de aspectos linguísticos e culturais, dentre outras coisas. Tal fato influencia a ampliação de acesso às diferentes línguas, evidenciando o caráter de fluidez e a condição de incessante mudança linguística. Em vista disso, a língua precisa ser vista como um processo de construção/produção de sentidos, uma vez que os sujeitos são parte de todo esse sistema móvel em qualquer espaço geográfico, que, por resultado da mundialização de serviços e produtos, acarreta fenômenos dispersos e diferentes.

Concomitante às transformações históricas, sociais e políticas que ocorreram nas últimas décadas, sucedeu-se uma nova forma de se pensar o conceito de língua e consequentemente o ensino de Língua Portuguesa (LP) na Educação Básica do nosso país. Além do mais, considerar os fluxos constantes na atual sociedade coloca as línguas, as pessoas e os discursos em uma situação de mobilidade, sendo "necessário repensar o que temos chamado de português" (MOITA LOPES, 2013, p. 19). Desse modo, achamos imprescindível fazer uma interface entre o ensino de línguas, tanto nacional, como estrangeira com as exigências que a atual conjuntura social e política nos traz.

Para falar acerca da noção de língua neste trabalho, tocamos, inevitavelmente, nos distintos meandros que cercam e constituem tal questão. Enredando esse caminho, Makoni e Pennycook (2007) nos auxiliam com uma colocação mestra: “as línguas não existem como entidades reais no mundo e nem emergem ou representam ambientes reais, elas são, ao contrário, invenções de movimentos sociais, culturais e políticos" (2007, p. 2, tradução minha). A partir do exposto, vislumbramos que, para tais autores, essas invenções influenciam na forma como as línguas foram constituídas por diferentes grupos sociais e de como as políticas linguísticas foram formuladas, influenciando, consequentemente, os caminhos que a educação tem seguido, em especial, no contexto brasileiro. 
REVISTA X, Curitiba, volume 13, n.2,p.47-66, 2018.

Pensando nisso, neste artigo propomos observar e analisar excertos das Diretrizes Curriculares da Educação Básica do Estado do Paraná (DCE), documento oficial de ensino de Língua Portuguesa. Tais excertos foram escolhidos por possibilitar traçar um caminho histórico-político da construção de uma certa noção de LP. Vale destacar que as DCE são frutos de uma política linguística que tem como objetivo nortear o ensino de LP na educação básica do Estado do Paraná, e, do mesmo modo, podem ser vistas como um veículo que permite a circulação de ideologias linguísticas que são criadas e autorizadas pelo Estado brasileiro e seguida por muitos professores.

Pretendemos ainda refletir acerca de como a língua e o ensino de LP foram construídos/discursivizados nesse documento, além de verificar a concepção de língua abordada nessa diretriz. Com a finalidade de direcionar o ensino, as DCE acabam possuindo uma influência decisiva na direção e desdobramento do ensino de LP no Estado do Paraná. Dessa forma, ocupam um lugar social de prestígio ao desempenhar um papel político-ideológico legitimador, pois tal política linguística tem a permissão significativa de dizer como e a partir de quais perspectivas deve ser ensinada a LP. Outrossim, sua escrita possibilita observar a partir de quais construtos teóricos essa língua foi construída no meio educacional. Igualmente, é relevante ressaltar que, embora se questione a maneira como a LP foi construída nesse documento, nosso foco não é impor qualquer crítica valorativa a escrita dessa diretriz, unicamente temos como finalidade expor uma visão diferente de percorrer pelo ensino.

Para análise deste trabalho, mobilizamos a ideia de rizoma de Deleuze e Guattari (2004). Para esses autores, no rizoma não há começo, nem meio, nem fim, isto é, não há um centro do qual se parta, ou seja, não há centro e nem periferia. Proporcionar tais reflexões a partir da ideia de rizoma é um grande desafio na área educacional, pois a construção do documento, a partir do nosso entendimento, segue uma trajetória linear, com início, meio e fim, isto é, não coaduna com a noção de rizoma proposta pelos autores. Dessa forma, procuramos questionar essa construção da noção de LP do documento a partir da ideia de rizoma, contrapondo com o conceito da árvore, bastante difundido e utilizado para explicar as representações do conhecimento humano.

Consideramos esse trabalho importante pela possibilidade de mostrar e debater acerca da visão homogênea de língua abordada pela diretriz e por ser seguida sem muito crível crítico por muitos professores, visto que a ênfase é apenas na língua oficial do estado, a LP, não considerando tantas outras línguas existentes no país, como por 
REVISTA X, Curitiba, volume 13, n.2,p.47-66, 2018.

exemplo as línguas indígenas ou até mesmo as línguas dos imigrantes que vivem no Paraná.

Essa concepção de língua(gem) deixa de lado o passado cultural e histórico dos povos que viviam no Brasil até o marco da colonização, além dos imigrantes que vieram para cá após a colonização portuguesa. Deste modo, entendemos que o Estado abraça a cultura do monolinguismo, a qual atribui uma única língua para a Nação e que acaba sendo tomada por muitos, ou melhor, imposta para muitos como a língua materna, nacional e oficial do país. A língua vista assim contribui para que o Estado alcance seus objetivos políticos e continue com o "poder" sobre um grupo de falantes.

Dividiremos este trabalho em três seções. Na primeira, abordaremos um estudo mais aprofundado acerca da língua como invenção política, fazendo uma interface com os trechos selecionados e as necessidades que o ensino de língua exige hoje no mundo em que vivemos. Na segunda, discorreremos acerca da ideia de árvore como representação do conhecimento humano e suas implicações para o ensino. Na terceira seção discutiremos sobre o conceito de rizoma, relacionando com o modo como a LP foi inventada e discursivizada no documento. Por fim, algumas considerações finais serão feitas a fim de retomar a ideia de como a LP e a concepção de língua do documento surgiu a partir de um processo político de invenção.

\section{DESINVENTANDO E REINVENTANDO AS LÍNGUAS}

Nesta seção faremos uma descrição histórica a partir de alguns recortes espaçotemporais que selecionamos do documento - DCE - para descrever os caminhos percorridos na construção do ensino de Língua Portuguesa encontrados nessa diretriz. Esse panorama abarca elementos históricos entre o século XVI até o momento da publicação desse documento - 2008, dando ênfase às mudanças históricas à medida que abrem espaço para que certas teorias e metodologias se assentem no campo do ensino de LP.

Para início da discussão, recorreremos a um conceito de língua enquanto uma invenção política, uma construção social. Dessa forma, propomos, neste trabalho, "repensar a língua como forma de possibilitar alternativas que possam ir além dela" (MAKONI; PENNYCOOK, 2007, p. 3), além de considerar que as línguas emergem como resultado de práticas sociais e não o contrário (PENNYCOOK, 2010). Portanto, observar as línguas em um processo contínuo de mudanças, traçar seus limites é algo 
REVISTA X, Curitiba, volume 13, n.2,p.47-66, 2018.

irrisório, a não ser que se tenha como objetivo descrevê-las em um espaço e tempo determinados.

Tal perspectiva de língua, tomada como uma invenção, ocasionou muitos impactos reais e concretos na maneira como essas línguas foram compreendidas e descritas, do mesmo modo como na maneira como as políticas linguísticas foram tratadas e, consequentemente, como a educação e o ensino discursivizaram essa língua. Essa forma de discursivização refletiu diretamente na maneira como as pessoas foram conduzidas a se identificarem com certos aspectos linguísticos e não outros.

Ademais, ao levar em conta que as línguas não são sistemas fixos e variam de acordo com vários aspectos, precisamos, no mundo em que vivemos hoje, desinventar e reconstruir essas línguas a partir de movimentos que implicam pensar na historicidade dessa invenção e nas maneiras como as línguas são vistas no século XXI, para então repensar sua inserção no mundo contemporâneo.

Segundo Makoni e Pennycook (2007), as línguas foram inventadas como elementos fundamentais de projetos coloniais e evangelizadores em diferentes partes do mundo, isto é, foram "inventadas, particularmente, como parte dos projetos cristãos/coloniais e nacionalistas" (MAKONI; PENNYCOOK, 2007, p. 1) e surgem a partir de relações de poder situadas, bem como servem a interesses políticos e econômicos específicos. Para tais autores, em relação às línguas, "os colonizadores europeus inventaram a si mesmos e os outros num processo recíproco. Assim, não foram inventadas apenas as línguas colonizadas, mas também as línguas dos colonizadores" (idem, p.8-9).

De acordo com o estudioso Errington (2001), a noção ocidental de língua surgiu a partir da filologia europeia que exerceu eficazmente seu papel de legitimar as diversidades humanas e coloniais. Segundo esse autor, a forma como as línguas foram tratadas no contexto colonial provocou hierarquizações, individualizações e a naturalização de desigualdades culturais e humanas. A título de exemplo, o latim foi tomado como modelo para o conhecimento de outras línguas, pois era considerado o cânone da língua estudada, da língua da Igreja Católica e da língua da Ciência, com isso, silenciava-se outras línguas.

Nessa perspectiva, uma passagem do documento-DCE confirma o domínio do Latim sobre outras línguas. No tocante às DCE, as primeiras instruções de ensino de LP no Brasil se deram a partir da educação jesuítica, ou seja, os jesuítas eram os responsáveis pela leitura e escrita ensinadas nas escolas. Essas primeiras práticas 
REVISTA X, Curitiba, volume 13, n.2,p.47-66, 2018.

pedagógicas eram marcadas pelo ensino do Latim e limitadas à alfabetização, "que visavam manter os discursos hegemônicos da metrópole e da Igreja." (PARANÁ, 2008, p.39). Portanto, observamos como o discurso da filologia europeia, nos tempos coloniais, influenciava nas práticas pedagógicas das salas de aula do Brasil. Ademais, tal paradigma europeu refletia na exploração de terras, do povo e das línguas, que, a partir daí, passaram a ser denominadas e descritas. Embora esse pensamento remeta à época colonial, não é muito diferente do que se vê ainda hoje. Dito de outro modo, o que ocorreu foi apenas um deslocamento dos responsáveis pelo poder, que passou da metrópole e da Igreja para o Estado.

Já no período colonial brasileiro a língua mais usada pela população era o tupi, enquanto o português era a língua dos negócios, das atividades comerciais e dos documentos legais. Ou seja, mesmo a língua tupi sendo a mais usada pelo povo, a língua do colonizado não era considerada para ser usada formalmente. Por conseguinte, a relação entre colonizado e colonizador ocasionou numa constituição da Língua Geral - tupi-guarani. O objetivo da utilização dessa língua pelos portugueses era somente com a finalidade de dominação desse novo local.

A constituição dessas línguas em relação ao processo de invenção linguística, de acordo com Makoni e Pennycook, incide na nomeação dessas línguas como entidades distintas, visto que "o ponto de maior significância é que não se tratavam de novos nomes para objetos existentes (línguas pré-existentes à nomeação), mas da invenção e nomeação de novos objetos. A nomeação performativamente deu existência às línguas" (MAKONI; PENNYCOOK, 2007, p. 10). Dessa forma, tais línguas foram inventadas de acordo com objetivos políticos e de dominação que o colonizador almejava.

A partir do século XVIII, com as expedições bandeirantes e a descoberta de riquezas em terra brasileira, a constituição da Língua Geral "passou a não interessar aos propósitos colonialistas de Portugal, que precisava manter a colônia e, para isso, a unificação e padronização linguística constituíram-se fatores de relevância." (PARANÁ, 2008, p.40). Nesse sentido, com o intuito da uniformização linguística vê-se como o colonizador construiu suas línguas e, nesse processo de construí-la a partir do interesse de torná-la hegemônica, fez com que permanecesse com o poder.

Isto posto, uma das primeiras estratégias adotadas pelo colonizador foi tornar hegemônica a LP em todo o país. Para essa medida se concretizar, em 1758, o Marquês de Pombal criou um decreto que tornava a Língua Portuguesa idioma oficial do Brasil, enquanto o uso da Língua Geral foi impedido. Em vista disso, a LP foi 
institucionalizada ainda no período colonial e, para que isso ocorresse, foi preciso um feito político jurídico, isto é, o Diretório dos Índios. Portanto, foi necessário um ato político para oficializar e institucionalizar forçadamente que era essa, e somente essa, a única língua que deveria circular no Brasil, e, ainda por cima, uma língua nos padrões da gramática portuguesa fixada pela Corte. Por esse ângulo, pode-se afirmar que

Trata-se da explicitação de uma política linguística como razão de uma nação, associada a um planejamento linguístico que impõe juridicamente uma língua, o que resulta na construção de uma unidade e de uma homogeneidade linguística, imaginariamente necessárias à hegemonia portuguesa na colônia. (MARIANI, 2004, p.149).

Após a Reforma Pombalina, a LP, seguindo ainda os moldes de ensino do latim, passou a fazer parte dos conteúdos curriculares. Anos depois, o ensino público encarregado pela alfabetização e catequese dos índios, passou a ser dirigido pela Metrópole com o objetivo de "modernizar a educação, tornando o ensino laico e colocando-o a serviço dos interesses da Coroa Portuguesa”. (PARANÁ, 2008, p. 41). O ensino, a partir desses interesses, discursivizaram uma certa ideia de LP que silenciava as vozes do colonizado e intensificava uma política de valoração social que privilegiava os falares vindos de Portugal em detrimento do falar brasileiro - tupi-guarani, construindo, assim, estereótipos coloniais do modo de falar do povo colonizado.

Segundo as DCE, foi em 1869 que a disciplina de LP passou a fazer parte da grade curricular brasileira e o latim começou a perder seu prestígio. Até essa época, as disciplinas clássicas eram priorizadas e o Português ficava em segundo plano. No final do século XIX, com o advento da República, a escola começou a receber cada vez mais um número maior da população. Dessa maneira, “o ensino de português tratava de prover uma determinada classe de uma língua que era considerada a 'boa língua' houve a tentativa de uma aprendizagem hierarquizada e seletiva." (PARANÁ, 2008, p.42). Nessa época, as gramáticas e os manuais didáticos foram escritos a partir de construções linguísticas particulares, em oposição às línguas usadas pelo povo brasileiro. Logo, essas políticas linguísticas reproduziam ainda uma visão eurocêntrica de língua, ao invés de refletir, de fato, acerca dos usos linguísticos brasileiros.

No entanto, com o aumento da população e a facilidade de acesso à escola pelo povo, o ensino precisou se reconfigurar. O Estado realizou várias iniciativas, as quais contribuíram para construir uma certa concepção de LP que estivesse ligada ao nacionalismo e a uma uniformidade linguístico-identitária brasileira. Nesse viés, a língua passou a ser reinventada a partir de outras necessidades particulares que vinham 
REVISTA X, Curitiba, volume 13, n.2,p.47-66, 2018.

surgindo. As estruturas e as línguas foram estabelecidas, reguladas e construídas a partir de fatores específicos e determinados. Ademais, essa ideia de invenção possibilitou intervenções sociais, políticas e linguísticas em relação às práticas homogeneizantes de língua, através da perspectiva da "desinvenção".

Com a valorização da língua nacional, o latim perdeu força e em 1922 com a consolidação do modernismo e uma literatura voltada ao nacionalismo, os autores modernistas contribuíram para que a língua escrita no Brasil se aproximasse do falar brasileiro. Na Era Vargas (1930-1945), a política linguística da época estava à serviço do Estado e procurava a definição de uma norma brasileira por meio de falas específicas da cultura nacional e alicerçada na opinião pública, em particular, na opinião das classes populares. Nesse viés, práticas linguísticas locais, que estavam distribuídas pelo Brasil, contribuíram para configuração de normas linguísticas consideradas brasileiras, principalmente as relacionadas às práticas orais e não letradas.

Entretanto, o que prevalecia eram os fenômenos de caráter político e social, e a noção de povo foi construída a partir de uma ideia homogênea impedindo, assim, a população de agir e falar por conta própria, dando continuidade ao silenciamento da língua do colonizado. Por isso, declara-se que muito do que se vê como tradição histórica de um grupo é, na verdade, uma invenção baseada em aspectos ideológicos e políticos muito específicos.

Ainda conforme as DCE, a partir de 1960 com o crescimento do ensino primário público houve um aumento significativo de alunos oriundos de diferentes classes e, com isso, as necessidades culturais estavam experimentando novos rumos.

[...] com a expansão quantitativa da rede escolar, passaram a frequentar a escola em número significativo falantes de variedades do português muito distantes do modelo tradicionalmente cultivado pela escola. Passou a haver um profundo choque entre modelos e valores escolares e a realidade dos falantes: choque entre a língua da maioria das crianças (e jovens) e o modelo artificial de língua cultuado pela educação da linguística tradicional; choque entre a fala do professor e a norma escolar; entre a norma escolar e a norma real; entre a fala do professor e a fala dos alunos. (FARACO, 1997, p. 57 apud PARANÁ, 2008, p.43)

A pluralidade cultural e linguística existente no Brasil, especialmente pela presença dos índios, africanos e imigrantes, fez com que emergisse e expandisse uma variedade do português brasileiro para todo país, isto é, uma diversidade linguística alicerçada nos falares brasileiros. Autores como Lucchesi, Baxter e Ribeiro (2009) defendem que o português brasileiro é fruto do contato entre o português europeu e as 
REVISTA X, Curitiba, volume 13, n.2,p.47-66, 2018.

línguas africanas, baseado no aprendizado equivocado da LP pelos africanos. Disso, afirmam os autores, resultou esse choque entre as variedades do português europeu e uma boa parte do que se encontra, hoje, de variedade linguística brasileira. Esse processo de criação e invenção das línguas conferiu uma maneira de constituição de desigualdade social entre essas variedades, pois privilegia-se uma, considerada a boa língua, em detrimento de outra, compreendida como uma língua inferior.

Nessa mesma época houve o fortalecimento da ditadura militar e o ensino baseava-se em uma concepção tecnicista de educação. Essa concepção nas aulas de LP resultava numa concepção de linguagem como "meio de comunicação (cujo objeto é a língua vista como código), com um viés mais pragmático e utilitário em detrimento do aprimoramento das capacidades linguísticas do falante.” (PARANÁ, 2008, p. 44). A língua vista como código é compreendida como um sistema fixo, e, ao ser concebida dessa forma, acaba por reificar as línguas ao invés de considerar seus falantes. Quando não se considera os falantes e a ênfase é numa abordagem que preconiza a normatividade da língua, esta é privilegiada em detrimento dos seus usos, fazendo com que um grupo de pessoas continue tendo sua voz silenciada.

Consoante aos documentos, em 1970 houve um grande avanço nos estudos da linguagem e diferentes teorias passam a ser discutidas no meio educacional, entre elas a Sociolinguística, Análise de Discurso, Semântica, Pragmática e Linguística Textual. Dessa discussão ocorreram indagações acerca da autoridade e eficácia das aulas de gramática e o conceito de língua precisou ser revisto novamente. No entanto, mesmo havendo toda essa inquietação, os livros didáticos continuaram priorizando uma concepção tradicional. Ou seja, "O ensino de Língua Portuguesa fundamentava-se, então, em exercícios estruturais, técnicas de redação e treinamento de habilidades de leitura." (PARANÁ, 2008, p. 44 a 45). Contudo, com a globalização e os avanços da tecnologia exigiu-se uma forma diferente de conceber a língua, de tal modo que demandou novas possibilidades de práticas de linguagem. Dessa forma, o ensino direcionado para uma perspectiva tradicional não condizia com as necessidades e conhecimentos que os alunos traziam consigo à sala de aula.

Com o fim do regime militar, os cursos de pós-graduação tiveram um aumento significativo e objetivavam a formação de professores a partir de um ensino crítico. Nesse momento houve a consolidação da pedagogia histórico-crítica, estabelecendo uma vertente progressista. Dessa forma, “A dimensão tradicional de ensino da língua cedeu espaço a novos paradigmas, envolvendo questões de uso, contextuais, 
REVISTA X, Curitiba, volume 13, n.2,p.47-66, 2018.

valorizando o texto como unidade fundamental de análise." (PARANÁ, 2008, p.46). Essa perspectiva significa pensar a língua além de seu sistema, significa procurar ver o que as pessoas fazem com a língua ao interagirem com outros sujeitos durante as práticas sociais. Dito de outro modo, exige-se "repensar, desinventar e reconstituir" (MAKONI; PENNYCOOK, 2007) noções de língua, a partir da desnaturalização de conceitos, acerca da linguagem, já consolidados.

Para as DCE, esse avanço em torno dos estudos da linguagem deu-se devido ao Círculo de Bakhtin, que criticava a concepção formal-sistemática, uma vez que tal concepção não considerava a abordagem histórica e viva da língua. Para Bakhtin e seus aliados, "a língua constitui um processo de evolução ininterrupto, que se realiza através da interação verbal social dos locutores" (BAKHTIN/VOLOCHINOV, 1999, p.127) e, portanto, compreendem-na como uma construção conjunta, considerando sempre a realidade história e social em que se realiza.

Após todas essas discussões e posicionamentos em relação ao ensino, tivemos como resultado a criação de tal documento, "numa proposta que dá ênfase à língua viva, dialógica, em constante movimentação, permanentemente reflexiva e produtiva. Tal ênfase traduz-se na adoção das práticas de linguagem como ponto central do trabalho pedagógico.” (PARANÁ, 2008, p.48). Ou seja, como bem coloca Pennycook (2010), considerar a maneira como a língua surge como produto dessas práticas e não o contrário.

\footnotetext{
Para alcançar tal objetivo, é importante pensar sobre a metodologia. Se o trabalho com a Língua deve considerar as práticas linguísticas que o aluno traz ao ingressar na escola, é preciso que, a partir disso, seja trabalhada a inclusão dos saberes necessários ao uso da norma padrão e acesso aos conhecimentos para os multiletramentos, a fim de constituírem ferramentas básicas no aprimoramento das aptidões linguísticas dos estudantes. (PARANÁ, 2008. P.48).
}

As DCE apresentam uma proposta a partir da diversidade linguística brasileira. Tal trabalho é direcionado mais ao regionalismo encontrado nas variedades linguísticas brasileiras, todavia, quanto às línguas indígenas, ainda ficam à margem. Observamos que, na prática, muito pouco se contempla acerca dessas influências linguísticas no falar brasileiro. As escolas até lembram do dia do índio, da consciência negra, mas pouco se discute acerca da presença indígena e africana na cultura do povo brasileiro. Nesse ponto até se argumenta a favor da variedade e do multilinguismo; todavia, o documento 
REVISTA X, Curitiba, volume 13, n.2,p.47-66, 2018.

cai na mesma armadilha ao se utilizarem de estratégias de pluralização, ao invés de interrogar as invenções que são a base de todo esse processo.

Nesse viés, um aspecto interessante de se ressaltar é que nesse processo de construção histórica do ensino de LP realizado pelo documento não há uma menção significativa de elementos culturais, linguísticos e discursivos dos povos que aqui viviam antes da colonização cuja presença foi fundamental na formação da identidade do português brasileiro. Essa diretriz enfatiza muito pouco, por exemplo, a existência das línguas indígenas, produzindo um apagamento que evidencia a maneira como essas línguas foram discursivizadas, ou seja, materializadas no meio educacional. As DCE, como uma política linguística, reproduzem pensamentos particulares e limitantes de como a língua funcionou nessa época e, que, no entanto, ainda refletem nas práticas atuais. Esse processo de invenção das línguas trouxe e ainda traz "consequências insidiosas para os povos indígenas" (MAKONI; PENNYCOOK, 2007, p. 23), conforme exemplo já citado.

Julgamos indispensável ressaltar que, embora marcado por um tempo e espaço instáveis e pela mobilidade de pessoas, culturas, etc., o ensino de línguas precisa, sim, ser pensado e revisto a partir das exigências que o mundo contemporâneo nos impõe, isto é, realizar um trabalho a partir da multiplicidade das variedades de línguas que há no Brasil, questionando as políticas linguísticas, desinventando e reinventando as línguas com base nas necessidades e anseios que as práticas nos proporcionam.

Autores como Canagarajah \& Wurr (2011, p.6) afirmam que estudos "baseados na homogeneidade e no monolinguismo" fracassam ao não considerar realidades multilíngues de grupos diversos. Infelizmente, como o documento prega apenas pelo ensino da LP, uma padronização linguística acaba sendo recorrente em sala de aula num contexto brasileiro. Deste modo, num país como o Brasil, é preciso levar em conta que o sujeito adapta seus "recursos de linguagem com suas necessidades e situações, ao invés de buscar atingir um nível-alvo de competência" (CANAGARAJAH; WURR, 2011, p.5). Portanto, a variedade no Brasil é algo inevitável, sendo a regra e não a exceção.

Moita Lopes (2008) também discute acerca do ensino de línguas na contemporaneidade e argumenta a favor de um estudo que anula uma teorização “fundada em uma língua nacional e, portanto, em um estado-nação que não parece fazer sentido no mundo constituído por fronteiras porosas em que vivemos" (MOITA LOPES, 2008, p.6). Dessa forma, um professor de línguas deve questionar e discutir 
REVISTA X, Curitiba, volume 13, n.2,p.47-66, 2018.

sempre com seus alunos que língua se fala e que língua se ensina no Brasil, pois as verdades tidas como absolutas e evidentes devem ser questionadas, visto que a verdade "é algo que é válido dentro de um tempo e de um espaço particulares" (MOITA LOPES, 2013, p.946), mas que nunca é incontestável.

Por fim, percebemos que esses documentos de ensino têm uma grande influência no processo de ensino de LP, e a forma como foram construídos fornece evidências de quais caminhos o professor deve seguir. A constituição dessas diretrizes, bem como as descrições linguísticas constituem uma forma de intervenção social, conforme nos adverte os autores: "Representações errôneas dessas realidades podem ter efeitos prejudiciais, mesmo se as descrições forem bem intencionadas" (MAKONI; MEINHOF, 2006, p. 192-193).

Podemos afirmar que tais documentos são criações convenientes a partir do objetivo que se quer chegar, fornecendo uma forma, considerada adequada na visão do Estado, de compreender o mundo e moldar o ensino. No entanto, acabam sendo também perigosos, na medida em que produzem visões específicas e limitadas de uma certa noção de LP. Nessa nossa leitura, buscamos estratégias de uma reinvenção e um olhar crítico acerca dos aspectos presentes nesse documento, pois este deve ser sempre o primeiro papel a ser realizado pelo professor que ensina línguas.

$\mathrm{Na}$ busca por estratégias, façamos importante compreender acerca de duas diferentes maneiras de conceber as representações do conhecimento humano, para, a partir disso, reconstruir e reinventar uma noção de LP que se identifique com as necessidades que o mundo contemporâneo traz e com uma possível resposta para a indagação de que língua falamos e que língua ensinamos.

\section{TRILHANDO O CAMINHO ARBORESCENTE}

Durante muito tempo e ainda praticado em muitos contextos, concebemos a ideia de árvore como a representação imagética do conhecimento humano. Este modelo representa o paradigma do pensamento a partir de ramificações, simbolizado por galhos que caracterizam os diversos conhecimentos e descobertas alcançadas pelo homem. De acordo com Deleuze e Guattari (2000b, p.28), a imagem da árvore como retrato do conhecimento orientou todo o pensamento ocidental da botânica à biologia, à anatomia, à gnosiologia, à teologia e toda à filosofia.

Esse modelo tornou-se tão representativo que são poucos os campos que se afastam dessa ideia arborescente. Nessa perspectiva há uma raiz estabelecida na base do 
conhecimento que sustenta todo o pensamento. Segundo Jordão e Fogaça, a metáfora da árvore transmite uma ideia de que as "[...] árvores possuem uma estrutura sólida, partindo de um único tronco, mas que se ramifica nas extremidades." (2012, p.496). Contrapondo essa ideia, Deleuze e Guattari afirmam que

\begin{abstract}
O pensamento não é arborescente e o cérebro não é uma matéria enraizada nem ramificada. O que se chama equivocadamente de "dentritos" não assegura uma conexão dos neurônios num tecido contínuo. A descontinuidade das células, o papel dos axônios, o funcionamento das sinapses, a existência de micro fendas sinápticas, o salto de cada mensagem por cima destas fendas fazem do cérebro uma multiplicidade que, no seu plano de consistência ou em sua articulação, banha todo um sistema probabilístico incerto, uncertain nervous system. Muitas pessoas têm uma árvore plantada na cabeça, mas o próprio cérebro é muito mais uma erva [daninha] do que uma árvore. (DELEUZE \& GUATTARI, 2000b p. 25)
\end{abstract}

A crítica desses autores não significa a exclusão do pensamento arborescente, o que pretendem é um olhar crítico para a hegemonia que esse pensamento expressa. Deste modo, um documento oficial de ensino que orienta para uma cultura do monolinguismo pratica essa concepção de árvore como uma estrutura fixa, pois as DCE, ao traçarem um caminho político e histórico que impõem a LP como língua única e oficial do Brasil, consolidam uma estrutura fixa, hegemônica e hierárquica de língua.

Para tais autores, a visão arborescente privilegia uma unidade principal e é a partir dela que as outras partes se unem. Assim, passam do "Uno a três, quatro ou cinco, mas sempre com a condição de dispor de uma forte unidade principal, a do pivô, que suporta as raízes secundárias" (DELEUZE; GUATTARI, 2004, p. 13). Desse modo, esse entendimento não concebe a compreensão de multiplicidade, portanto, é nesse sentido que a LP se torna a unidade principal de língua falada no Brasil, enquanto as outras variedades são apenas secundárias, por vezes, nem consideradas línguas e sim apenas dialetos. Por isso, compreende-se que

\footnotetext{
Os sistemas arborescentes são sistemas hierárquicos que comportam centros de significância e de subjetivação, autômatos centrais como memórias organizadas. Acontece que os modelos correspondentes são tais que um elemento só recebe suas informações de uma unidade superior e uma atribuição subjetiva de ligações preestabelecidas. (DELEUZE \& GUATTARI, 2000b p. 26). P.11
}

A ideia do estudo arborescente prega pela organização estrutural hierárquica do pensamento, a qual resulta no intento de início, meio e fim. No caso deste trabalho, a metáfora da árvore propicia pensar como a construção da LP como língua materna, nacional e oficial do país reflete o monolinguismo praticado aqui, além da exclusão e 
silenciamento de muitas outras línguas faladas no país. Seguir esse caminho retrata a maneira como a língua é pensada homogeneamente e de forma estruturalmente organizada em políticas linguísticas responsáveis por direcionar o ensino. O documento, que tem o papel de orientar professores, não questiona acerca da construção de como a LP se constituiu e como foi imposta no Brasil, apenas repete, reafirma todo o pensamento pós-colonial já fixado.

Por muito tempo a cultura arborescente respondeu aos questionamentos impostos pelo mundo; no entanto, com a globalização, os avanços tecnológicos e muitos outros desenvolvimentos, necessitamos de uma reconfiguração desse pensamento com ênfase na busca de diferentes modelos que deem conta de explicar esse processo de construção do conhecimento a partir da multiplicidade de línguas. Nesse sentido, Deleuze e Guattari apontam para uma proposta rizomática.

\section{DESVENDANDO O CAMINHO ABERTO DO RIZOMA}

Contrapondo a ideia da árvore, o modelo rizomático funciona a partir de outra lógica, qual seja, não mais a da ideia de estrutura organizada e hierárquica que "dá lugar ao desenvolvimento imprevisível, flexível, não hierárquico.” (JORDÃO; FOGAÇA, 2012, p.499). Deleuze e Guattari descrevem o rizoma como estando sempre no meio, não possuindo um início, um meio e um fim. Nesse sentido, os autores esclarecem que,

\footnotetext{
Um rizoma não começa nem conclui, ele se encontra sempre no meio, entre as coisas, inter-ser, intermezzo. A árvore é filiação, mas o rizoma é aliança, unicamente aliança. A árvore impõe o verbo "ser", mas o rizoma tem como tecido a conjunção "e... e... e...". Há nesta conjunção força suficiente para sacudir e desenraizar o verbo ser. Para onde vai você? De onde você vem? Aonde quer chegar? São questões inúteis (DELEUZE; GUATTARI, 2004, p. $37)$.
}

No livro Mil Platôs, os autores descrevem algumas características que subjazem a ideia rizomática. São elas: $1^{\circ}$ e $2^{\circ}$ princípios de conexão e heterogeneidade; $3^{\circ}$ princípio de multiplicidade; $4^{\circ}$ princípio de ruptura a-significante; $5^{\circ}$ e $6^{\circ}$ princípio de cartografia e de decalcomania.

Nos princípios de conexão e heterogeneidade, os autores ressaltam que qualquer ponto do rizoma pode ser conectado a outro ponto na mesma estrutura. Dessa forma, não há uma ordem fixa e linear, mas apenas linhas e caminhos independentes que se entrecruzam. Nessa perspectiva, entendemos que, com a cultura do monolinguismo, a LP passou a representar o centro de onde tudo se parte, estabelecendo uma estrutura fixa 
e invariável de língua. No entanto, a partir da ideia de rizoma, compreendemos que a LP é apenas um ponto que se liga a tantas outras línguas também faladas no país, as quais registram os diferentes falares que se entrecruzam e constituem as identidades culturais e linguísticas encontradas aqui. Justificamos essa compreensão através do que Deleuze e Guattari abordam:

[...] não há universalidade da linguagem, mas sim um concurso de dialetos, de patoás, de gírias, de línguas especiais. (...) A língua é, segundo uma fórmula de Weinreich, "uma realidade essencialmente heterogênea". Portanto, é impossível pensar em "uma língua-mãe", mas somente em uma "tomada de poder por uma língua dominante dentro de uma multiplicidade política" (DELEUZE e GUATTARI, 2004: 16).

Isto posto, é possível observar que a LP é considerada a língua dominante no Brasil, e que foi estabelecida a partir de jogos políticos e históricos, de forma que "a unidade de uma língua é sempre inseparável da construção de uma unidade política". (GUATTARI, 1988, p.25). No entanto, pensar a LP como língua dominante silencia e exclui a diversidade linguística do país.

Seguindo essa ideia de multiplicidade, os autores propõem o princípio da multiplicidade como também caracterizando o conceito de rizoma. Para eles, pensar a multiplicidade significa que não há mais relação alguma com o uno, dessa forma, não há um pivô central de onde os ramos se partam, ou seja, há "Inexistência, pois, de unidade que sirva de pivô no objeto ou que se divida no sujeito." (DELEUZE E GUATTARI, 2004, p.16). À vista disso, os autores coadunam com esta noção rizomática "que se desenvolve evitando toda orientação sobre um ponto de culminância ou em direção a uma finalidade exterior" (DELEUZE e GUATTARI, 2004, p.33). Por isso que o ponto de culminância do ensino de língua materna não deve estar totalmente voltado somente para a aquisição da LP mas também, deve-se abrir margens para que todas as línguas tenham voz no espaço educacional e entre tantos outros.

O quarto princípio elencado por Deleuze e Guattari é o princípio de ruptura asignificante. Segundo esse princípio, um rizoma pode ser quebrado em qualquer lugar e, ao mesmo tempo, retoma uma ou outras de suas linhas, nunca sendo a mesma, já que a quebra já a alterou. A cada quebra as linhas não param de acometer-se umas às outras, excluindo a possibilidade de unicidade. Para exemplificar essa visão, os autores se utilizam da metáfora da correição de formigas, a qual se forma constituindo uma nova estrutura. Nessa perspectiva, 
[...] todo rizoma compreende linhas de segmentaridade segundo as quais ele é estratificado, territorializado, organizado, significado, atribuído, etc.; mas compreende também linhas de desterritorialização pelas quais ele foge sem parar. Há ruptura no rizoma cada vez que linhas segmentares explodem numa linha de fuga, mas a linha de fuga faz parte do rizoma (DELEUZE; GUATTARI, 2004, p. 18).

Consideramos ser possível fazer referência à ideia da quebra, da ruptura com todas as possibilidades linguísticas que emergem nos falares brasileiros, isto é, a ruptura ou ao menos a tentativa de ruptura de unificação/padronização da língua estabelecida imaginariamente como a língua da norma padrão. As línguas representam as linhas de um rizoma que, ao serem colocadas em prática, se rompem a todo momento e se constituem a cada contexto e necessidade de uso, remetendo-se umas às outras, quando necessário.

Por fim, o $5^{\circ}$ e $6^{\circ}$ princípios, chamados de princípio da cartografia e de decalcomania, são concebidos em oposição à ideia do decalque. De acordo com esse princípio, "um rizoma não pode ser justificado por nenhum modelo estrutural ou gerativo." (DELEUZE e GUATTARI, 2004, p.21). Dito de outro modo, um rizoma não pode ser compreendido por nenhuma disposição fixa, estruturada, por isso considera-o como um mapa. Um mapa aberto, “[...] conectável em todas as suas dimensões, desmontável, reversível, suscetível de receber modificações constantemente." (idem, p.22).

Ver o rizoma como um mapa é entendê-lo como apto a ser desmontável, conectável a qualquer uma de suas partes, suscetível a encaixes de qualquer propriedade, ser (re)planejado por qualquer sujeito e grupo social. Dessa maneira, suas possibilidades são múltiplas, "[...] contrariamente ao decalque, que volta sempre ao mesmo". (DELEUZE e GUATTARI, 2004, p.22). Pensar o ensino de LP como um mapa é concebê-lo a partir de sua multiplicidade linguística, cultural, social, sem prestigiar apenas uma língua como a boa língua, a boa fala, mas sim dar voz a todas as línguas, pois como um mapa, toda língua está sujeita a receber modificações, montagens, encaixes e não ser tratada como um elemento fixo e irreversível.

Jordão e Fogaça (2012, p.502) constroem um quadro comparativo entre a árvore e o rizoma, que segue abaixo para melhor exemplificá-los. 


\section{QUADRO 1}

Quadro comparativo entre a árvore e o rizoma

\begin{tabular}{|l|l|}
\hline \multicolumn{1}{|c|}{ ÁRVORE } & \multicolumn{1}{c|}{ RIZOMA } \\
\hline Estrutura & Sistema \\
\hline Genealogia & Antigenealogia \\
\hline Linearidade & limprevisibilidade \\
\hline Hierarquia & Transgressão \\
\hline Ciclos com início, meio e fim & Intermezzo \\
\hline Pivô central & Trama neural, Multiplicidade \\
\hline Continuidade & Ruptura a-significante \\
\hline Reproduçăo, decalque & Mapas \\
\hline
\end{tabular}

Fonte: JORDÃO e FOGAÇA (2012, p.502).

Portanto, nos apoiando na noção de língua como invenção, nas necessidades que o mundo contemporâneo reivindica e nas transformações no ensino de língua, observamos que a noção de LP construída pelo documento deve ser reinventada a partir da ideia de rizoma, pois assim pode ser que o ensino contemple melhor uma maior diversidade linguística que dê voz a todos os grupos sociais e culturais.

\section{CONSIDERAÇÕES FINAIS}

Esse trabalho tratou de considerar como os discursos de um documento oficial que rege o ensino de LP na educação básica do país, produzido pelo Estado, constroem uma dada concepção de língua a partir de regimes discursivos específicos, legitimando essa construção para fins políticos e educacionais variados, visto que essa diretriz fundamenta o discurso oficial e reconhecido que rege as práticas pedagógicas do ensino de LP no estado do Paraná.

Ademais, a maneira como a língua foi construída, tratada e inventada nesse documento permite visualizar como o Estado tem abordado uma noção de língua em uma instância política-educacional que no imaginário acaba com as desigualdades sociais. No entanto, ao propor como língua padrão o ensino apenas da LP finaliza por confirmar que a distribuição do poder linguístico no Brasil continua inconsistente. Dessa forma, "por mais bem intencionado politicamente, deve incorporar formas de compreender os efeitos perniciosos que ele pode engendrar, a menos que confronte a necessidade da reconstituição da língua" (MAKONI; PENNYCOOK, 2007, p. 28). 
REVISTA X, Curitiba, volume 13, n.2,p.47-66, 2018.

Portanto, nas práticas de ensino de língua, os professores devem estar atentos às questões expostas, já que, no menor dos gestos linguísticos, a dominação da língua hegemônica tende a irromper.

Políticas linguísticas alicerçadas em línguas inventadas revelam que documentos oficiais de ensino podem, sim, valorizar as línguas presentes no Brasil, bem como as suas variedades, dando-lhes voz, escolarizando-as e transformando-as em línguas que constituam a identidade do povo brasileiro. Desse modo, com os avanços na educação, um documento de ensino não deve somente partir de um único olhar, mas traçar outros caminhos possíveis. A construção de sentidos do documento não pode partir somente de quem mantém o poder - o Estado, porquanto deve apoiar-se também em todos os envolvidos nesse processo, desde o aluno da educação básica, professores, sociedade e governo. Não havendo uma hierarquização de poder, fundamenta-se a ideia de rizoma como uma forma de representar o conhecimento humano e compreender que língua se fala e que língua se ensina no Brasil.

Outrossim, como ressalta Makoni e Pennycook (2007, p. 30), as direções conceituais empregadas em projetos de "desinvenção" e (re)constituição das línguas precisam se distanciar do totalitarismo das ações coloniais e se adequar de acordo com os problemas que vão se colocando, sendo que o mais apropriado não seria pensar em soluções, mas em alternativas possíveis para questão. Assim, as línguas, em contínuas transformações, não necessitam ser estabelecidas por meio de uma concepção históricapolítica única implementada pelo Estado. Nesse viés, adotando o conceito de rizoma, sempre se perguntará que língua se fala e que língua se ensina.

Ainda segundo Makoni e Pennycook (2007), esse projeto de "desinvenção" das línguas, alicerçado em construções sócio-históricas, políticas e culturais determinadas, tem como objetivo salientar a evidência de que aspectos linguísticos não conseguem abordar por completo uma língua e nem constituir a existência dessa língua. Dito isso, faz-se necessário o reconhecimento significativo de processos sociais e semióticos que influenciam nessa invenção. Fica claro, portanto, que a noção de língua padrão precisa ser reinventada quando a linguagem é utilizada para se produzir sentido em práticas sociais do dia a dia, visto que o que interessa é o modo como o sujeito significa ao produzir sentidos no mundo. O ensino de língua, nesse viés, está além de limites de uma língua nacional única, isto é, ultrapassa as fronteiras que foram estabelecidas imaginariamente, diferente, pois, da forma como aspectos linguísticos são considerados e apresentados. 
REVISTA X, Curitiba, volume 13, n.2,p.47-66, 2018.

Quando o documento prioriza metodologias que prezam um ensino a partir das vivências cotidianas, o conceito de língua é desinventado e reconstituído fundamentando-se nas necessidades do dia a dia. Em consequência, os indivíduos desenvolvem suas estratégias de negociação com a finalidade de produzir sentidos durante suas interações sociais.

Por fim, constatamos que o documento é construído a partir da metáfora da árvore arborescente, pois não compreende a ideia de multiplicidade e o multilinguismo realizáveis no país. Todavia, vale destacar que não se está criticando a escrita dessa diretriz, apenas se tem como objetivo mostrar uma maneira diferente de percorrer a prática do ensino de LP no Paraná.

\section{REFERÊNCIAS}

CANAGARAJAH, Suresh \& Adrian WURR. 2011. Multilingual Communication and Language Acquisition: New research directions. The Reading Matrix, v. 11, n. 1.

DELEUZE, Gilles \& GUATTARI, Félix. Mil Platôs: capitalismo e esquizofrenia. Vol. I. São Paulo, Ed. 34. 2004.

DELEUZE, Gilles \& GUATTARI, Félix. Mil Platôs: capitalismo e esquizofrenia, Vol. 1, Tradução de Aurélio Guerra Neto e Célia Pinto Costa. Rio de Janeiro: Ed. 34, 2000b.

ERRINGTON, J. Colonial Linguistics. Annual Review of Anthropology, Palo Alto, v.30, p.19-39, 2001.

GUATTARI, Félix. O inconsciente maquínico: Ensaios de esquizo-análise. Campinas, Papirus. 1988.

JORDÃO, C.; FOGAÇA, C. Carvalhos, juncos, árvores e rizomas: paradigmas na formação de professores. RBLA, Belo Horizonte, v.12, n.3, p.493-510, 2012.

LUCCHESI, D.; BAXTER, A.; RIBEIRO, I. (Org.). O Português Afro-Brasileiro. 1 Ed. Salvador: EDUFBA, 2009.

MAKONI, Sinfree; PENNYCOOK, Alastair (Ed.). Disinventing and reconstituting languages. Clevedon: Multilingual Matters, 2007.

MAKONI, S.; MEINHOF, U. Linguística aplicada na África: desconstruindo a noção de "língua". Tradução de Luiz Paulo da Moita Lopes. In: MOITA LOPES, L. P. (Org.). Por uma linguística aplicada indisciplinar. São Paulo: Parábola, 2006. p. 191-213.

MARIANI, Bethânia. Colonização linguística. Campinas: Pontes, 2004. 
REVISTA X, Curitiba, volume 13, n.2,p.47-66, 2018.

MOITA LOPES, Luis Paulo. Inglês e globalização em uma epistemologia de fronteira: ideologia linguística para tempos híbridos. DELTA, v. 24, n. 2, p.1-15, 2008.

MOITA LOPES, Luis Paulo. Linguística Aplicada na Modernidade Recente: Festschrift para Antonieta Celani. São Paulo: Parábola, 2013.

PENNYCOOK, A. Language as a local practice. Londres; Nova York: Routledge, 2010. 